\title{
Major sickle cell disease and pregnancy: about 24 cases observed in a reference structure in Senegal (National hospital of pikine)
}

\begin{abstract}
Objective: To study the management and the prognosis of sickle cell disease in its homozygous (SS) and composite (SC) forms, this is particularly morbid when it is associated with pregnancy, in the quest to propose a protocol for its management.

Patients and methods: This were a retrospective, descriptive and analytical study carried out at the Pikine National Hospital Center, in suburb of Dakar, over a period of four successive years, from April 1, 2009 to July 31, 2019. Were included all pregnant women with major sickle cell syndrome who gave birth in hospital. Data entry and analysis were done by the Statistical Package of Social Science (SPSS) and Excel software.

Results: We identified twenty-four (24) pregnant women with major sickle cell disease, representing an overall prevalence of $0.1 \%$. The average age was 27.2 years. The SS phenotype was the most found with Twenty-two cases $(91.6 \%)$. Their average pregnancy rate was 1.5 pregnancies. The majority $(53.8 \%)$ were diagnosed with sickle cell disease during the current pregnancy, in the event of a vaso-occlusive crisis or during a systematic pregnancy check-up. The average hemoglobin level was $7.7 \mathrm{~g} / \mathrm{dl}$ with extremes of $10.1 \mathrm{~g} / \mathrm{dl}$ and $2.3 \mathrm{~g} / \mathrm{dl}$. Urogenital infections were present in $50 \%$ of cases. One case of gonalgia was noted in a patient with an SS phenotype. The average gestational age at delivery was around 31.7 weeks with extremes of 26 to 39 weeks. Thirteen (13) pregnancies were complicated by intrauterine growth restriction (IUGR) in SS patients. The stillbirth rate was 125\%. We noted $69.2 \%$ of live births, $23.1 \%$ of intra uterine fetal death and $7.7 \%$ of abortions. Almost half of the patients ( 13 cases) had received a postpartum blood transfusion

Conclusion: The results of our study perfectly show the seriousness of this pathology and the importance of rigorous hematological management. This is a pregnancy at high risk of maternal-fetal complications requiring appropriate obstetric follow-up, which must be based on several axes: pregnancy planning, multidisciplinary follow-up, screening for signs of severity and supervised management of acute accidents.
\end{abstract}

Keywords: sickle cell disease, type SS and SC, pregnancy, complications, multidisciplinary, pregnancy planning, Urogenital infections, gestational age, gonalgia, intrauterine growth, retrospective, vaso-occlusive
Volume 8 Issue 6 - 2019

\author{
Moussa Diallo,Abdoul Aziz Diouf, Aminata \\ Niass, Astou Coly Niassy Diallo, Babacar \\ Biaye, Hadja Maimouna Barro Daff, Codou \\ Sene Seck, Anna Dia, Aminata Sophie \\ Coulbary, Mory Niang, Alassane Diouf \\ Department of obstetrics \& gynecology unit, National hospital \\ of pikine, Senegal
}

Correspondence: Moussa Diallo, Department of obstetrics gynecology Unit, National Hospital of Pikine, located in Thiaroye Camp, Dakar, Senegal, Tel 33853007 I Email moussadiallo25@hotmail.com

Received: November 03, 2019 | Published: December 09 2019

\section{Introduction}

Sickle cell disease is a genotypic condition characterized by the presence of a hemoglobin $\mathrm{S}$ which results biologically and clinically suckling red blood cells and hemolytic anemia. ${ }^{1,2}$ The occurrence of pregnancy in this fragile situation can trigger fearsome maternal and fetal complications even when appropriate preventive measures are used. Management must be multidisciplinary, involving obstetrician, hematologist and pediatrician assisted by different specialists depending on the evolution. Progress in these areas has allowed women to reach reproductive age and even pregnancy with the risk of complications for them and their fetus. For this, early detection of the disease is essential to plan the best time to be pregnant. In view of this context of pregnancy, which deserves great attention, we have decided to conduct a study on the association of major sickle cell disease and pregnancy at the Pikine National Hospital Center. The main objective is to study the management and prognosis of this particularly morbid pathology when it is associated with pregnancy, in the quest to propose a protocol for its management.

\section{Patients and methods}

It was a retrospective, descriptive and analytical study carried out in one of the national reference structures, the Pikine National Hospital Centre, over a period of four consecutive years from 1 April 2009 to 31 July 2017. Were Included all pregnant women with major sickle cell syndrome who gave birth in this maternity. Data entry and analysis were done by the SPSS and Excel software.

\section{Results}

\section{A. Prevalence and characteristics of patient}

We had identified 24 pregnant women with major sickle cell disease, representing an overall prevalence of $0.09 \%$. The average age was 27.2 years with extremes of 19 and 36 years. The SS phenotype was the most found with 23 cases $(95.8 \%)$. The SC phenotype was found in one case with a frequency of $4.1 \%$. The average pregnancy rate was 1.5 pregnancies with extremes of 1 and 4 . The average parity in our population was 1.2 children with extremes of 0 and 3. A patient's 
SC sickle cell status was discovered following complications (vasoocclusive seizures and death) of her fourth pregnancy. No obstetrical pathological history has been found. For the majority (53.8\%), sickle cell disease was diagnosed during the current pregnancy, in the face of a vaso-occlusive crisis or a systematic pregnancy check-up.

\section{B. Prenatal follow-up}

Patients were referred late to our structure. They were admitted at an average gestational age of 30 weeks. Prenatal follow-up was weak before their referral. The quality of prenatal care was not the best with a low number of prenatal consultations, on average 2 per woman. None of the patients received a pre-conception check-up or prophylactic transfusion.

\section{Fetal prognosis}

Ten pregnancies were complicated by intrauterine growth restriction (IUGR) in SS patients. We note 11 cases of prematurity, including 2 cases induced by caesarean section of caution with the birth of 2 eutrophic newborns. The stillbirth rate was $125 \%$. We noted $69.2 \%$ of live births, $23.1 \%$ fetal death in utero and $7.7 \%$ abortion cases (Figure 1). The average gestational age at delivery is around 31.7 weeks with extremes of 6 to 39 weeks (Figure 2).

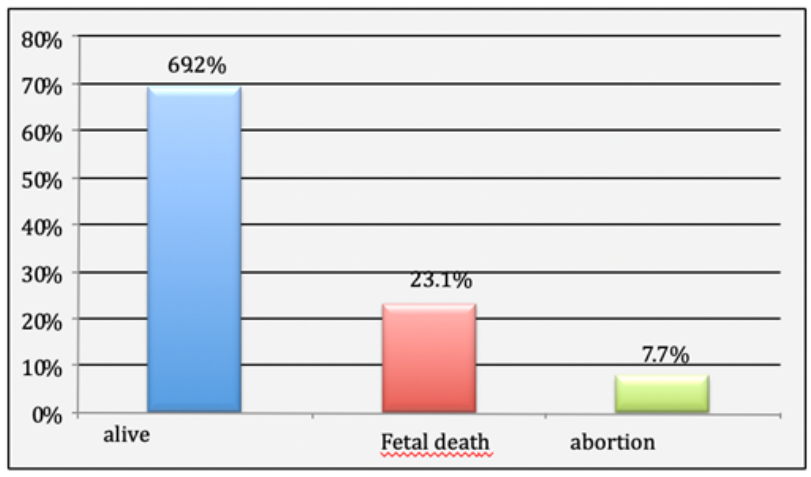

Figure I Fetal and neonatal outcome.

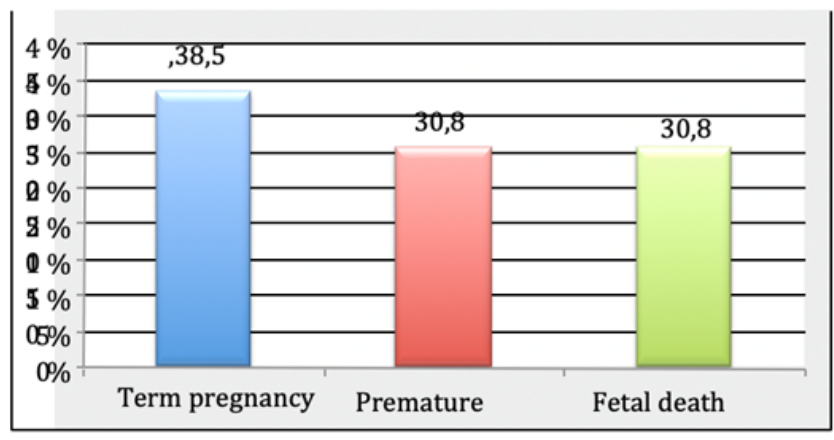

Figure 2 Age of pregnancy at the time of delivery.

\section{Maternal prognosis}

The average hemoglobin level was $7.7 \mathrm{~g} / \mathrm{dl}$ with extremes of $10.1 \mathrm{~g}$ $/ \mathrm{dl}$ and $2.3 \mathrm{~g} / \mathrm{dl}$. Urogenital infections were present in 50\% of cases. A case of gonalgia was noted in an SS patient. Eighty-seven-point five percent $(87.5 \%)$ of deliveries were performed by cesarean section, including one performed urgently for a vaso-occlusive crisis. Almost half of the patients had received a postpartum transfusion. Maternal mortality was $0.8 \%$ (one case concerning the SC type). The (Table 2) resumes all characteristics of our patients.

\section{Discussion}

\section{a) Limits of the study}

It was a retrospective study. In our study, almost all our patients were received from the second, third trimester of pregnancy or in the presence of a complication. This meant that no patient reported complete information about their history before pregnancy.

\section{b) Prevalence and characteristics of patient}

Out of 24615 patients received at the maternity from April 1, 2009 to July 31, 2017, twenty-four cases of major sickle cell disease associated with pregnancy were recorded, representing $0.09 \%$ of patients. This rate is similar to the one found by Mounanga., ${ }^{2}$ in Gabon. It remains low compared to the sickle cell population, which is about $1 \%$ in Senegal according to Diagne's study. ${ }^{3}$ The average age of the patients (27.2 years) shows that this is a young population, in the middle of a period of genital activity; however, the parity of 1.2 children is low and reflects limited procreation in the population with major sickle cell syndrome. No cases of pre-pregnancy screening were mentioned in the files. Pregnancy is thus the first factor favoring the detection of sickle cell disease in our series. This screening during pregnancy does not improve the prognosis of this combination since the woman will not have been clinically or biologically prepared by a pre-conception check-up that would have improved her condition. In our context, a family survey could be conducted among all women of childbearing age. Otherwise, early screening should be mandatory for all women in the first trimester of pregnancy, especially since there are asymptomatic heterozygous composite patients whose diagnosis is made only during a complication during pregnancy.

\section{c) Prenatal follow-up}

In our series, no patients had received specific follow-up for sickle cell disease. The average number of prenatal consultations was 2 and the absence of consultation in hematology indicates that the management of this association is insufficient within the health chain in terms of quantity and quality. In our series, the average rate of consultations is well below the number recommended by the World Health Organization, which since 2016 has been advocating 8 prenatal consultations for a normal pregnancy in order to improve the quality of prenatal care to reduce the risk of stillbirth and pregnancy complications and provide women with a positive experience of pregnancy. ${ }^{4}$ The maternal risk, in case of pregnancy, is multiplied by 100 and the fetal risk by 10 , even for moderate forms of the disease as in heterozygous composite patients. ${ }^{5}$

\section{d) Maternal prognosis}

Maternal morbidity observed in our series at the time of pregnancy was dominated by anemia with an average hemoglobin level of $7.7 \mathrm{~g} /$ $\mathrm{dl}$. This rate is higher than those found by Diallo $(6.9 \mathrm{~g} / \mathrm{dl})$. Bonkian in France, found an average hemoglobin level of $6.99 \mathrm{~g} / \mathrm{dl}$ with extremes of $5 \mathrm{~g} / \mathrm{dl}$ and $10 \mathrm{~g} / \mathrm{dl} .{ }^{6}$ Diagne objectives a rate of severe anemia (less than $7 \mathrm{~g} / \mathrm{dl}$ ) which was $51.7 \%$. Chronic anemia, which is quite well supported by the sickle cell patient during pregnancy, does not often lead to transfusion. ${ }^{4}$ However, it has adverse effects on fetal morbidity by causing significant fetal risks such as intrauterine growth retardation (10 to $21 \%$ ) and increased prematurity ( 9 to $45 \%) .7$ Thus, no genotype of major sickle cell disease can be excluded a priori from the risk of serious complications.

In Leborgne's study, 17 of 68 patients presented a postpartum complication with $51.5 \%$ for SS and $10 \%$ for SC. ${ }^{7}$ Most often it was 
an aggravation of the anemia requiring a transfusion. Two patients with an SS phenotype had severe hypoxemia on day 2 postpartum and severe anemia associated with painful seizures requiring transfusion. Prophylactic transfusion would have reduced the significant maternal and fetal morbidity observed in our series. Indeed, in recent years, the obstetrical debate has focused on the realization of systematic prophylactic blood transfusions during pregnancy, more precisely from 26 weeks, allowing the hemoglobin $\mathrm{S}$ level to be reduced to less than $40 \%$ in order to reduce complications and emergency transfusions. ${ }^{4,8,9,10}$ Maternal death can be sudden and unexplained, or occur in a particular context of care difficulties. ${ }^{7}$ Between 1979 and 1985, Attal., ${ }^{4}$ had analyzed 63 cases. He reported 2 maternal deaths in 2 SC patients following massive pulmonary embolism at 35 weeks and eclampsia and acute lung edema at 34 weeks.

The predominant route of delivery in our series was cesarean section with 21 cases, or $61.5 \%$ of cases. Four cesarean sections were performed as a precaution, 3 cases as a necessity and only one case was performed in a vaso-occlusive crisis emergency situation.

Table I Characteristics of patients

\begin{tabular}{llllll}
\hline Hemoglobin type & Number $(\mathbf{n})$ & Percentage \% & Mean age & Mean Gestity & Mean Party \\
\hline SS phenotype & 23 & 95,8 & 27,3 & 1,5 & 1,2 \\
SC phenotype & 1 & 4,2 & 35 & 4 & 4 \\
\hline
\end{tabular}

Table 2 Main maternal complications

\begin{tabular}{|c|c|c|}
\hline Maternal complications & SS type (N / \%) & SC type (N / \%) \\
\hline \multicolumn{3}{|l|}{ Vaso-occlusives crisis } \\
\hline \multicolumn{3}{|l|}{ Effective // percentage \% : 8 // 33.3\% } \\
\hline During pregnancy & $6 / 75 \%$ & $1 / 100 \%$ \\
\hline In the post partum & $2 / 25 \%$ & 0 \\
\hline \multicolumn{3}{|l|}{ Anaemia } \\
\hline \multicolumn{3}{|l|}{ Effective // percentage $\%: 24 / / 100 \%$} \\
\hline Under 8 & $6 / 25 \%$ & $0 / 0 \%$ \\
\hline Between 8-9 & $8 / 33.3 \%$ & $1 / 100 \%$ \\
\hline Supérieur à 9 & $9 / 37.5 \%$ & $0 / 0 \%$ \\
\hline \multicolumn{3}{|l|}{ Urogénital infection } \\
\hline Effective // percentage $\%$ : $50 \%$ & $1 \mathrm{I} / 45.8 \%$ & $1 / 4,16 \%$ \\
\hline \multicolumn{3}{|l|}{ Transfusion } \\
\hline \multicolumn{3}{|l|}{ Effective // percentage $\%: 9 / / 37.5 \%$} \\
\hline During pregnancy & 0 & 0 \\
\hline In the post-partum & $6 / 50 \%$ & 0 \\
\hline \multicolumn{3}{|l|}{ Caesarian-section } \\
\hline \multicolumn{3}{|c|}{ Effective // percentage $\%: 21 / / 87.5 \%$} \\
\hline \multicolumn{3}{|l|}{ Emergencies } \\
\hline vaso-occlusive syndrome & 0 & $1 / 100 \%$ \\
\hline IUGR, prééclampsia & $12 / 50 \%$ & 0 \\
\hline Of caution & $9 / 37.5 \%$ & 0 \\
\hline \multicolumn{3}{|l|}{ Maternal death } \\
\hline \multicolumn{3}{|l|}{ Effective // percentage $\%: 2 / / 0.8 \%$} \\
\hline During pregnancy & I & 0 \\
\hline In the post-partum & 0 & I / 100\% \\
\hline
\end{tabular}




\section{e) Fetal and perinatal prognosis}

Perinatal morbidity in our study was dominated by prematurity $(30.8 \%)$ and urogenital infection $(50 \%)$. Hypoxia caused by chronic maternal anemia and the occurrence of vaso-occlusive events, particularly in the placenta, and infections are probably the two main causes of fetal morbidity. Stillbirths were not very severe in our series with a rate of $125 \%$ versus $333 \%$ in the Diallo series. Perinatal mortality is reduced by more than half compared to Diallo's results. This result is correlated with an improvement in management during pregnancy after referral to a referral center. A spontaneous abortion rate of $7.7 \%$ was characteristic of our series. Our results are lower than those of Diallo (24\%). The fetal death $(23.1 \%)$ is very high compared to those found in the literature or rates ranging from 7 to $14 \%{ }^{11,12}$ This is probably due to the late referral, but also to the underestimation of fetal risk by the medical team and the lack of knowledge of the underlying sickle cell site in some cases. Indeed, in our series, fetal death occurred during hospitalization during a vaso-occlusive crisis at 34 weeks in a previously non-phenotyped major sickle cell SC, which was the only one to die from the consequences of its complication in our sample..$^{4,13}$

\section{Conclusion}

At the end of our study we propose some recommendations:

In the absence of systematic screening of all women of childbearing age, perform routine neonatal screening, to look for irregular antibodies if the test is positive, to have an optimal rate of hemoglobin notably by the systematic transfusion in per-partum same avoid all the precipitating factors the cold crisis, track the infection especially urinary (thus cyto-bacteriological examination of urine once a month and hydration) and respiratory in the postpartum. To ensure optimal weight gain, to control the vaccinations, perform an ultrasound and a general hematological assessment from 26weeks, between 28 and 36weeks, increase screening for preeclampsia (frequency $30 \%$ ), placental insufficiency and premature detachment of placenta normally inserted, about 38 weeks to give birth, and finally perform respiratory physiotherapy for prevention (in the postpartum) or curative (neuropathy, acute thoracic syndrome).

\section{Acknowledgments}

None.

\section{Conflicts of interest}

The author declares that there are no conflicts of interest.

\section{Funding}

None.

\section{References}

1. Berkane N, Nizard J, Dreux B, et al. Drépanocytose et grossesse : complications et prise en charge. Pathologie Biologie. Paris : Elsevier. 1999, vol. 47, n॰1, p. 46-54.

2. Mounanga M, Awassi-Ndouono A, Zinsou RD. Drépanocytose majeure et fécondité. J. Gynéco Obst Biologie Reprod 1986; 19 : 77.

3. Diagne I, Tchamago CJ, Bampoki P, et al. Dépistage néonatal de la drépanocytose au Sénégal : Étude préliminaire dans deux maternités de Dakar XVI journées médicales, Dakar Fev 2006.

4. Attal JP, Latay-Pillet MC, Taurelle R. De l'intérêt des transfusions prophylactiques systématiques dans l'évolution des grossesses chez les drépanocytaires majeures. Étude de 63 accouchements en Guadeloupe. J Gynecol Obstet Biol Reprod. 1987;16(6):787-793.

5. Ferster A, Kentos A, Bradstreet C, et al. La drépanocytose : une affection exotique ou un problème de santé publique en Belgique ? Revue Médicale de Bruxelles. 2005;26(4):309-313.

6. Bonkian C. Drépanocytose et grossesse : revue de 13 observations à la Maternité Régionale Universitaire A PINARD. Université Henri Poincaré, 2009;41-50.

7. Leborgne-Samuel Y, Janky E, Vendittelli F. Drépanocytose et grossesse : revue de 68observations en guadeloupe. J Gynecol Obstet Biol Reprod. 2000;29(1):86-93.

8. Diallo D, Ngabo D, Sy M, et al. Particularité de la grossesse et de l'accouchement chez les drépanocytaires majeures au CHU Aristide Le Dantec à Dakar. Journal de la SAGO. 2009;10(2):1-6.

9. Red Blood Cell Group - Belgian Hematological Society 2006.

10. Benirschke K, Kaufmann P. Pathology of the human placenta. Third edition New York: Springer-Verlag. 1995.

11. Lansac J, Berger C, Magnin G. Drépanocytose. Obstétricien pour le praticien. SIMEP. 1989:220-221.

12. Embury SH, Steinberg MH. Clinical considerations. In: Embury SH, Hebbel RP(editors). Sickle Cell Disease Basic Principles and Clinical Practice. Raven Press. 1994:505-734.

13. Goldcher A, Galacteros F, Bachir D. Diagnostic clinique de la drépanocytose. In: La drépanocytose. 1997:11-15. 